\title{
Evoked potential evidence for a stripe-rearing effect on rat visual cortex
}

\author{
J. A. LONDON and WILLIAM T. GREENOUGH \\ University of Illinois, Urbana-Champaign, Illinois
}

\begin{abstract}
Restricting visual experience to lines of one orientation during development modifies visual cortex physiology in cats but not in rabbits. To test the importance of binocular convergence in this stripe-rearing species difference, hooded rats, which, like the rabbit, have a highly decussated visual system, were studied. Subjects were reared in darkness and binocularly exposed, for 25 to $40 \mathrm{~h}$ during the $3 \mathrm{rd}$ to 7 th weeks after birth, to a visual field of vertical or horizontal stripes. Visual cortical evoked potentials to stroboscopically illuminated vertical and horizontal stripe stimuli were recorded during the 8 th week. The relative amplitude of the early positive component of the visually evoked potential was greater for stimuli matching the rearing orientation than for stimuli of the opposite orientation. Evoked responses to stimuli of other orientations were generally smaller than those to the exposure orientation. In rats reared in normal cyclic light or in total darkness, there were no differences in the response to vertical vs. horizontal stripe stimuli. The results indicate that evoked potentials are modified by developmental restriction of experience to oriented contours without differential input to the eyes in an organism with limited binocular convergence.
\end{abstract}

The activity of single units in cat visual cortex can be modified by selective exposure to stripes at a single orientation during development. Hirsch and Spinelli (1970), using stripes fixed in goggles, and Blakemore and Cooper (1970), using exposure to a striped drum, reported that the majority of orientationsensitive cells examined had receptive fields which tended to be aligned around the orientation of the exposure stimuli. More recently, the conditions under which this phenomenon occurs in the cat have been investigated. For example, several recent papers (Blakemore, 1977; Blasdel, Mitchell, Muir, \& Pettigrew, 1977; Stryker, Sherk, Leventhal, \& Hirsch, 1978) have noted the probable importance of restricting head movement or stimulus position such that the desired orientation of the stimuli is maintained. In addition, it appears that the effects are more pronounced when input to the two eyes is asymmetric (Gordon, Presson, Packwood, \& Scheer, 1979; Stryker et al., 1978). Gordon et al. (1979) suggest that asymmetric exposure has more effect because a cell with an inherent orientation selectivity will preferentially

The research was supported by NSF BNS 7723660 and NSF SER 76 18255. We thank Howard Rowley for assistance with experimental procedures, Gregory McCarthy for technical advice, JoAnna Mitchell for excellent manuscript preparation, and Theodore Bashore for critical comments on earlier drafts. The authors are associated with the Departments of Physiology and Biophysics (J.A.L.) and Psychology and Anatomical Sciences and the Program in Neural and Behavioral Biology (W.T.G.) at the University of Illinois. Correspondence may be addressed to W. T. Greenough, Department of Psychology, University of Illinois, 603 East Daniel Street, Champaign, Illinois 61820. maintain its connections with the eye receiving input that more closely matches the cell's orientation selectivity. These two effects together may account for the inconsistencies in drum-rearing studies (e.g., Stryker \& Sherk, 1975).

With rare exceptions, electrophysiological studies of stripe-rearing have been performed in cats, in which binocular competition appears to play an important role in visual development (Guillery, 1972; LeVay, Wiesel, \& Hubel, 1980). One study in rabbits, in which visual cortex cells are largely monocular, found no effect of stripe rearing on visual cortical receptive field orientation (Mize \& Murphy, 1973). This, taken with the Gordon et al. (1979) conclusion, suggests that binocular competition may be essential for the occurrence of stripe rearing effects on cellular connections in the visual cortex.

The rat, like the rabbit, has only a small binocular area of visual cortex (Montero, 1973) and most of its retinal fibers cross to the opposite side of the brain. However, in contrast to work in rabbits, anatomical, physiological, and behavioral studies in rats have suggested that the developing visual system is sensitive to light deprivation (e.g., Fifkova, 1970; Rothblat \& Schwartz, 1979; Shaw, Yinon, \& Auerbach, 1974; Tees, 1976). Thus, the rat may provide a better test of the importance of a binocularly interactive visual system to the development of orientation selectivity under conditions of selective exposure.

Previous studies have assessed stripe-rearing effects from receptive fields of individual visual cortex cells. We chose instead to examine the visual evoked potential (VEP) in occipital cortex to stroboscopically illumi- 
nated stripe stimuli. The VEP is a summed average of electrical activity in an area that is analyzed on the basis of peak amplitude and latency of onset. Recent work suggests that EP techniques can be used to assess various aspects of visual function, including the development of responsiveness to luminance change (Dustman, Snyder, Creel, \& Beck, 1979; Glass, Fromm, Chattha, \& Bloom, 1978), the effects of early visual deprivation (Glass, 1971, 1973, 1977; Jones \& Berkeley, 1977), the sequence of pattern processing in visual areas (Lieb \& Karmel, 1974), and clinical cerebral dsyfunction syndromes (Dustman, Snyder, Callner, \& Beck, 1979). We analyzed the VEPs recorded in rats reared with different binocular visual experiences. Our experimental rats were exposed to either vertical or horizontal stripes during development. We then recorded the VEPs in these two groups to stimuli that were either similar or dissimilar in orientation to the rearing stimuli. In addition, we compared the VEPs with the same stimuli in dark reared and cyclic light reared rats.

\section{METHODS}

\section{Subjects and Rearing Procedures}

Subjects were Long-Evans hooded rats (stock source: Simonsen Laboratories, Gilroy, California). Pigmented male littermates were assigned randomly to one of four experimental conditions during the second week after birth. These groups consisted of: horizontal striped environment $(H, N=8)$, vertical striped environment $(V, N=7)$, dark reared $(D, N=3)$, and cyclic light reared $(L, N=4)$. For Groups $H, V$, and D, litters were raised in plastic tub-type cages; the cages were contained in a ventilated lightproof box. For the L group, the cages were identical to those of the previous groups but were housed in a separate animal room.

Exposure to horizontal or vertical stripes began on the day the eyes opened, ranging from Day 10 to Day 14. Exposure continued for 5 weeks. To ensure relatively stable exposure to striped fields, the animals' limbs were bound and their bodies were wrapped in cheesecloth after Blasdel et al., 1977). Thus immobilized, they were placed in a small box, the head extending beyond the edge, such that the sides of the box were largely outside the visual field. The box was placed on the floor of a 25 -cm-diam, 26-cm-tall cylinder, with the head centered $12.5 \mathrm{~cm}$ from the sides. The inside of the cylinder contained stripes of varying widths (from 2.5 to $10 \mathrm{~mm}$, or approximately .5 to 5 cycles/deg of visual angle). The order in which the stripes appeared was determined randomly. Three $\mathrm{V}$ rats were exposed to vertical stripes for $2 \mathrm{~h} /$ day, 4 days/week, and four rats were exposed to vertical stripes for $1 \mathrm{~h} /$ day, 5 days/week. Four $\mathbf{H}$ rats were exposed to horizontal stripes for $2 \mathrm{~h} /$ day, 4 days/week, and four were exposed $1 \mathrm{~h} /$ day, 5 days/week. All pre- and postexposure handling and maintenance of these animals took place in dim red light, and the remainder of their time was spent in the dark. Animals in Group D were handled in dim red light for periods equivalent to those necessary to set up the $\mathrm{H}$ and $\mathrm{V}$ animals. $\mathrm{L}$ group animals were on a 12-h-light/12-h-dark cycle.

\section{Recording Procedures}

On Day 52, stainless steel wires or stainless steel skull screws were unilaterally or bilaterally implanted over areas 17 and 18 of the visual cortex ( $5 \mathrm{~mm}$ lateral and $7 \mathrm{~mm}$ posterior to bregma). A third electrode was implanted over the frontal cortex to be used as a reference electrode. One week after implantation, unanesthetized animals were tested for VEPs to various stimuli.
In the test situation, the subjects were immobilized, with their limbs once again bound and their bodies wrapped in cheesecloth. The board on which they lay was affixed to a ring stand at a constant distance of $15 \mathrm{~cm}$ from the stimuli. This configuration allowed the animals to be tested in a consistent way, with stimuli being viewed from the correct orientation, without the use of drugs.

Stimuli were stroboscopically illuminated for $300 \mathrm{msec}$ at the rate of $1 \mathrm{flash} / \mathrm{sec}$. The light was arranged so that no shadow fell across the stimuli or the visual field of the subject. Stimuli consisted of stripes in a horizontal or vertical orientation on a three-quarter circular field around the subject. Stripes in each stimulus varied randomly from .5 to 5.0 cycles/deg of visual angle. Signals were recorded using a Grass Model 79 polygraph and averaged by a Fabritek signal averager (Model 1052H). The averager sweep was triggered by the leading edge of the stroboscope pulse. Sixty-four signals were averaged for each stimulus trial, 1 signal/stimulus, 64 signals/trial. A 2 -min recovery period was allowed between trials. For all $\mathrm{L}$ and $\mathrm{D}$ animals and four $\mathrm{H}$ and $\mathrm{V}$ animals, a second average was collected for each stimulus $10 \mathrm{~min}$ after the end of the first trials.

\section{RESULTS AND DISCUSSION}

The VEP of all subjects possessed the same general characteristics. A large, positive-going component of the waveform appeared $100 \mathrm{msec}$ after stimulation (Figure 1) in all subjects. This component, referred to as the P100, was observed to clearly differ in amplitude as a result of exposure conditions and in response to different stimuli.

VEPs were assessed by measuring the amplitude of the first positive deflection relative to the preceding negative peak (Figure 1). This amplitude was standardized by dividing the amplitude of the test VEP by the amplitude of the VEP to the exposure stimuli (determined by a coin toss for $L$ and $D$ an-

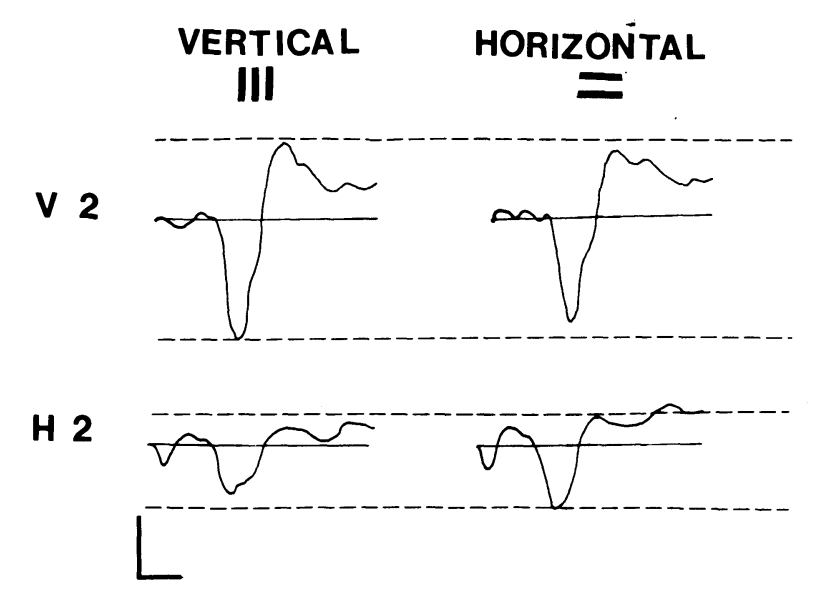

Figure 1. Averaged evoked potentials from a vertical stripe exposed rat, V2, and a horizontal stripe exposed rat, H2, to horizontal and vertical stimuli (hand traced from photographs). The solid line indicates EEG amplitude at stimulus onset. The dashed lines indicate points at which the amplitude measurements were made for the stimulus similar to the exposure environments (V2, vertical; H2, horizontal). Calibration mark: for $\mathrm{V2}, 50 \mu \mathrm{V}, 50 \mathrm{msec}$; for $\mathrm{H2}, 100 \mu \mathrm{V}, 50 \mathrm{msec}$ (up is negative). 
Table 1

Relative Amplitude of P100 in Response to Stimuli of Various Orientations (Rearing Exposure Orientation $=1.00$ )

\begin{tabular}{|c|c|c|c|c|c|}
\hline Animal & Horizontal & Vertical & Right 45 Deg & Left 45 Deg & Random \\
\hline \multicolumn{6}{|c|}{ Horizontal Exposure Group } \\
\hline 1 & 1.00 & .74 & & & \\
\hline 2 & 1.00 & .64 & .69 & .81 & .66 \\
\hline 3 & 1.00 & .57 & & & \\
\hline 4 & 1.00 & .90 & 1.08 & .92 & .92 \\
\hline 5 & 1.00 & 1.56 & & & \\
\hline 6 & 1.00 & .95 & & & \\
\hline 7 & 1.00 & .62 & .85 & .66 & .76 \\
\hline 8 & 1.00 & .77 & & & \\
\hline \multicolumn{6}{|c|}{ Vertical Exposure Group } \\
\hline 1 & .96 & 1.00 & & & \\
\hline 2 & .82 & 1.00 & .68 & .83 & .84 \\
\hline 3 & .88 & 1.00 & .82 & .85 & .90 \\
\hline 4 & .91 & 1.00 & & & \\
\hline 7 & .73 & 1.00 & & & \\
\hline 8 & .80 & 1.00 & .86 & .88 & .86 \\
\hline 10 & .84 & 1.00 & & & \\
\hline \multicolumn{6}{|c|}{ Dark-Reared Group* } \\
\hline 1 & 1.00 & .99 & .86 & .99 & .86 \\
\hline 2 & .94 & 1.00 & .88 & 1.03 & .94 \\
\hline 3 & 1.00 & 1.06 & .98 & 1.06 & 1.08 \\
\hline \multicolumn{6}{|c|}{ Light-Reared Group* } \\
\hline 1 & 1.00 & 1.05 & .82 & .98 & .96 \\
\hline 2 & 1.00 & 1.00 & .86 & 1.00 & .86 \\
\hline 3 & .88 & 1.00 & 1.25 & 1.75 & $\begin{array}{l}.00 \\
.88\end{array}$ \\
\hline 4 & 1.00 & 1.00 & 1.06 & .58 & .52 \\
\hline
\end{tabular}

*Exposure orientation assigned by coin toss.

imals), giving a relative response ratio. These measurements were taken by hand and were made blind (the person analyzing the data was unaware of the exposure or test condition). These standardized responses to the same stimulus from the same animal but from different hemispheres and different trials were averaged to obtain one value for each animal. Electrodes without clearly visible average evoked potentials (possibly due to bad electrode connections or heavy scar tissue formation) were excluded from the analysis $(\mathrm{N}=3)$. The results were evaluated statistically using the sign test (Siegel, 1956).

Average data for each subject appear in Table 1. For $\mathrm{H}$ animals, P100 amplitude averaged $19 \%$ larger to horizontal than to vertical stimulus presentation, and the subjects' responses differed by sign test $(\mathrm{N}=\mathbf{8}$, $\mathrm{X}=1, \mathrm{p}<.05$ ). For $\mathrm{V}$ animals, the mean difference was $13.1 \%$, favoring the vertical stimulus $(N=7$, $X=0, p<.01$; for combined groups: $N=15, X=1$, $\mathrm{p}<.001)$. There was no significant or apparent difference between responses to the two orientations in $\mathrm{D}(.05 \%, \mathrm{~N}=3, \mathrm{X}=1, \mathrm{p}>.25)$ and $\mathrm{L}(5 \%, \mathrm{~N}=4$, $X=2, p>.25)$. For all $L$ and $D$ rats and three $H$ and $\mathrm{V}$ rats, responses to three additional stimuli, right 45 , left 45 , and randomly oriented lines were recorded. In $\mathrm{H}$ and $\mathrm{V}$ animals, responses to these stimuli were generally smaller than those to the exposure orientation. P100 amplitude to the random stimulus was generally comparable to that for the oblique stimuli (Table 1).

These results indicate (1) that evoked potential methods can reveal effects of developmental restriction of experience to lines of a single orientation, (2) that selective experience of this sort affects visual cortex physiology in the rat, and (3) that the effect occurs in the rat without differential input to individual eyes. A variety of effects of visual deprivation upon characteristics of evoked potentials have been reported (Fox, Inman, \& Glisson, 1968; Glass, 1971, 1973, 1977; Jones \& Berkley, 1977). In general, variations in species, anesthetic conditions, duration of deprivation, and other procedural aspects make general conclusions difficult. However, some studies in which, as in the present study, no anesthetic was used during recording have reported a diminution in evoked potential components in deprived subjects (e.g., Baxter, 1966; Lindsley, Wendt, Lindsley, Fox, Howell, \& Adey, 1964), and similar results are not uncommon when anesthetics are used (e.g., Mitzdorf \& Singer, 1980; Myslivecek \& Stipek, 1979; Snyder \& Shapley, 1979). Given these prior findings, it seems reasonable to suggest that the VEP amplitude differences may reflect differences in the neural response to stimulus orientation, although the possibility that background activity changes are involved cannot be discounted. 


\section{REFERENCES}

Baxter, B. L. Effect of visual deprivation during postnatal maturation on the electroencephalogram of the cat. Experimental Neurology, 1966, 14, 224-237.

BlaKemore, C. Genetic instructions and developmental plasticity in the kitten's visual cortex. Philosophical Transactions of the Royal Society, B (London), 1977, 278, 425-434.

Blakemore, C., \& Cooper, G. Development of the brain depends on the visual environment. Nature, 1970, 228, 477-478.

Blasdel, L. L., Mitchell, D. E., Muir, D. W., \& Petrigrew, J. D. A physiological and behavioral study in cats of the effect of early visual experience with contours of a single orientation. Journal of Physiology (London), 1977, 265, 615-636.

Dustman, R. E., Snyder, E. W., Callner, D. A., \& Beck, E. C. The evoked response as a measure of cerebral dysfunction. In H. Begleiter (Ed.), Evoked brain potentials and behavior. New York: Plenum Press, 1979.

Dustman, R. E., Snyder, E. W., Creel, D., \& Beck, E. C. Ontogeny of the visual evoked response in the stump-tailed macaque. Developmental Psychobiology, 1979, 12, 161-167.

Fifkova, E. The effect of monocular deprivation on the synaptic contacts of the visual cortex. Journal of Neurobiology, 1970, 1, 285-294.

Fox, M. W., Inman, O., \& Glisson, S. Age differences in central nervous effects of visual deprivation in the dog. Developmental Psychobiology, 1968, 1, 48-54.

GLAss, J. D. Photically evoked potentials in cat neocortex altered by visual pattern deprivation. Brain Research, 1971, 30, 207-210.

Glass, J. D. Photically evoked potentials from cat neocortex before and after recovery from visual deprivation. Experimental Neurology, 1973, 39, 123-139.

GLASS, J. D. Photic evoked activity in the visual cortex of monocularly deprived cats. Experimental Neurology, 1977, 55, 211-225.

Glass, J. D., Fromm, G. H., Chatтha, A. S., \& Bloom, R. D. Postnatal development of visually evoked activity within motor cortex of cat. Journal of Neurophysiology, 1978, 41, 1007-1013.

Gordon, B., Presson, J., PAckwood, J., \& Scheer, R. Alteration of cortical orientation selectivity: Importance of asymmetric input. Science, 1979, 204, 1109-1111.

Guille RY, R. W. Binocular competition in the control of geniculate cell growth. Journal of Comparative Neurology, 1972, 144, 117-130.

Hirsch, H. V. B., \& Spinelli, D. N. Visual experience modifies distribution of horizontally and vertically oriented receptive fields in cats. Science, 1970, 168, 869-871.

Jones, K. R., \& BerkLeY, M. A. Distribution and temporal response characteristics of evoked potentials in the visually deprived cat. Brain Research, 1977, 130, 572-578.
LeVay, S., Wiesel, T. N., \& Hubel, D. H. The development of ocular dominance columns in normal and visually deprived monkeys. Journal of Comparative Neurology, 1980, 191, 1-51.

LiEB, J. P., \& KARMEL, B. Z. The processing of edge information in visual areas of the cortex as evidenced by evoked potentials. Brain Research, 1974, 76, 503-519.

Lindsley, D. B., Wendt, R. H., Lindsley, D. G., Fox, S. S., Howell, J., \& ADEY, W. R. Diurnal activity, behavior and EEG response in visually deprived monkeys. Annals of the New York Academy of Sciences, 1964, 117, 564-587.

MitzdoRf, U., \& Singer, W. Monocular activation of visual cortex in normal and monocularly deprived cats: An analysis of evoked potentials. Journal of Physiology (London), 1980, 304, 203-220.

Mize, R. R., \& MurPhy, E. H. Selective visual experience fails to modify receptive field properties of rabbit striate cortex neurons. Science, 1973, 180, 320-323.

Montero, V. M. Evoked responses in the rat's visual cortex to contralateral, ipsilateral and restricted photic stimulation. Brain Research, 1973, 53, 192-196.

MysliveceK, J., \& STipeK, S. Effects of early visual and complex stimulation on learning, brain biochemistry, and electrophysiology. Experimental Brain Research, 1979, 36, 343-357.

Rothblat, L. A., \& Schwartz, M. The effect of monocular deprivation on dendritic spines in visual cortex of young and adult albino rats: Evidence for a sensitive period. Brain Research, 1979, 161, 155-161.

Shaw, C., Yinon, U., \& Auerbach, E. Diminution of evoked neuronal activity in the visual cortex of pattern deprived rats. Experimental Neurology, 1974, 45, 42-49.

SIEGEL, S. Nonparametric statistics for the behavioral sciences. New York: McGraw-Hill, 1956.

Snyder, A., \& Shapley, R. Deficits in the visual evoked potentials of cats as a result of visual deprivation. Experimental Brain Research, 1979, 37, 73-86.

Stryker, M. P., \& Sherk, H. Modification of cortical orientation selectivity in the cat by restricted visual experience: $A$ reexamination. Science, 1975, 190, 904-905.

Stryker, M. P., Sherk, H., Leventhal, A. G., \& Hirsch, H. V. B. Physiological consequences for the cat's visual cortex of effectively restricting early visual experience with oriented contours. Journal of Neurophysiology, 1978, 41, 896-909.

TEES, R. C. Perceptual development in mammals. In G. Gottlieb (Ed.), Neural and behavioral specificity. New York: Academic Press, 1976.

(Manuscript received February 22, 1982; accepted for publication February 26, 1982.) 